\title{
Reperfusion times for ST elevation myocardial infarction: a prospective audit
}

\author{
Kendeep S Kaila, Kapil M Bhagirath*, Malek Kass, Lorraine Avery, Lillian \\ Hall, Alex H Chochinov, James W Tam
}

\begin{abstract}
Background: New published guidelines recommend treatment of ST elevation myocardial infarction (STEMI) within 30 minutes of first medical contact to thrombolysis and 90 minutes to primary percutaneous coronary intervention (PCI). Objectives: To determine how a tertiary care center compares to these new guidelines and to evaluate the success of measures directed to shorten delays. Methods: This was a prospectively designed audit loop using retrospective chart review. Specific time intervals were evaluated: 1) T2 (ER presentation to diagnostic EKG; 2) T ER (ER presentation to reperfusion); and 3) T AHA (first medical contact to reperfusion). Results of the initial 12-month data were conveyed to Emergency Room staff and a dedicated EKG machine was placed in the ER for the subsequent 12 months, and the results were then re-analyzed. Results: In 2003-4, 58 patients with STEMI were identified, with $41(70.7 \%)$ receiving reperfusion. Of those receiving thrombolysis, median T AHA was 54 [37-72] minutes, with $12.0 \%<30$ minutes, while those receiving PCI, median T AHA was 58 [43-78] minutes, with $25.0 \%<90$ minutes. In 2004-5, 52 patients had STEMI, with $40(76.9 \%)$ receiving reperfusion. The percentage of patients meeting the guidelines was $14.3 \%$ for the thrombolysis group and $11.1 \%$ for the PCI group. Introduction of a dedicated EKG machine led to a strong trend towards improvement in median $T 2$ (22 vs 10 minutes; $P=0.07$ ), but other treatment times remained unchanged. Conclusions: Treatment times are longer than recommended guidelines. More comprehensive strategies and improved coordination of medical services are required to shorten pre-contact and post-contact response times.
\end{abstract}

KEYWORDS: ST elevation myocardial infarction, reperfusion times, ACC/AHA guidelines

\section{INTRODUCTION}

Acute myocardial infarction (AMI) is a leading cause of morbidity and mortality in Canada. The Canadian Cardiovascular Outcomes Research Team (CCORT) showed that there were 139,523 new AMI cases in Canada between 1997/98 and 1999/2000, with an in-

*To whom correspondence should be addressed: Dr. Kapil Bhagirath, c/o Dr. James W. Tam Y3005 - 409 Tache Avenue, Winnipeg, MB, Canada R2H $2 \mathrm{~A} 6$

Tel: (204) 478-1777

Fax: (204) 787-1623

umbhagir@cc.umanitoba.ca hospital mortality rate of $12.3 \%$ (1). In the treatment of acute ST elevation myocardial infarctions (STEMI), both thrombolysis and percutaneous coronary intervention (PCI) are proven reperfusion strategies to decrease mortality (2-8). The initial landmark thrombolysis trials demonstrating a mortality benefit were completed in the late 1980's and early 1990's (24). A meta-analysis of these trials published in 1994 demonstrated an absolute mortality benefit of $3 \%$ at 5 weeks in those patients treated within 6 hours of symptom onset (5). In a further advancement, the primary PCI trials demonstrated improved outcomes when compared to thrombolysis $(6,7)$. For example, in 
the DANAMI-2 trial, the primary end-point of mortality, re-infarction, and stroke at 30 days was seen in $8 \%$ of patients receiving PCI and $13.7 \%$ of patients receiving thrombolysis (7).

Nonetheless, the optimal treatment modality has continued to be an ongoing and contentious issue in cardiovascular medicine (9-10). A recent review of 23 clinical trials by Keeley et al. suggests that primary PCI is more effective than thrombolysis in reducing death and non-fatal reinfarction (8). An essential caveat to this is that the benefit achieved by timely reperfusion by thrombolysis may be just as effective as PCI if there are imminent delays foreseen in receiving PCI. Hence, more important than the choice of initial reperfusion strategy is the concept of receiving treatment in a timely fashion, thus producing a similar degree of myocardial salvage (11).

The 2004 American College of Cardiology/American Heart Association (ACC/AHA) guidelines recommended that thrombolysis or PCI be administered within 30 or 90 minutes of first medical contact, respectively (12). These new guidelines were also reviewed and adapted for Canada by the Canadian Working Group (CWG) (13). It should be noted that these modifications were made from previous ACC/AHA guidelines established in 1999, which required thrombolysis or PCI to be administered within 30 or 90 minutes of arrival to hospital (14). With the emphasis on timely treatment of STEMI, the objective of our present study was to investigate how a tertiary care center in Winnipeg compared to these new guidelines over a 12 month period, looking specifically at the various components of time delay in patients receiving either thrombolysis or primary PCI. In this prospectively designed closed-loop audit, we subsequently made an attempt to rectify in-hospital time delays by introducing a dedicated EKG machine to the Emergency Room (ER) and by providing feedback on the previous year's data to the ER staff. We then reevaluated treatment times in the subsequent 12 months.

\section{METHODS}

\section{Study Design and Patient Population}

This was a retrospective chart audit designed prospectively to improve in-hospital time delays for timely reperfusion. The audit initiative was put forth by the Section of Cardiology within the Departments of Medicine and Cardiac Sciences and the Department of Emergency Medicine. The protocol was consistent with standards developed for audit-based research in the Winnipeg Regional Health Authority (WRHA) and the University of Manitoba. Coded 'myocardial infarction' charts were analyzed at St. Boniface General Hospital initially between September $1^{\text {st }}, 2003$ and August 31 ${ }^{\text {st }}$,
2004. Then, on September 1, 2004, a dedicated EKG machine was introduced to the ER, and the next year's charts were subsequently analyzed (September 1, 2004 and August 31, 2005). Furthermore, information from the initial year's audit was conveyed to the ER staff. Inclusion criteria included patients of at least 18 years of age presenting with STEMI, as per the definition consistent with ACC/AHA guidelines. Patients included in the study were either direct walk-ins to the ER or presented via EMS. Patients with NSTEMI, transferred MI, and in-hospital or peri-operative MI were excluded. There was no established mechanism developed in deciding whether patients received PCI or thrombolysis. In general, patients received PCI if there were clear contraindications to thrombolysis, a pre-shock/shock state was present, or if the cardiac catheterization suite was conveniently available (ie: selective daytime PCI).

\section{Data Collection}

The data was collected by one of three authors (KB, MK, KK). A fourth investigator (JWT) was available in difficult cases, whereby decisions were made by consensus. Data was recorded on standardized forms designed by our investigative group, containing information pertaining to patient demographics, clinical presentation, and specific time intervals. Figure 1 below illustrates the specific time intervals.

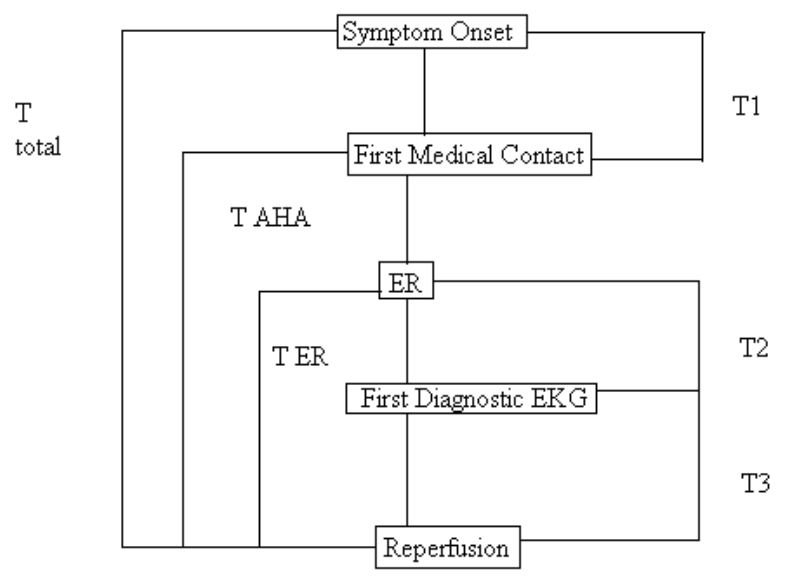

Figure 1: Flow diagram illustrating various components of the treatment times analyzed in this study.

The patient-dependent time interval $\mathrm{T} 1$ represents the elapsed time from symptom onset to first medical contact, which could be in the form of direct presentation to the ER or via EMS activation. Other important time intervals include: 1) T2 (time from ER presentation to first diagnostic EKG), 2) T3 (time from diagnostic EKG to reperfusion), 3) T ER (time from ER presentation to reperfusion, or 'door-to- needle/balloon' time), and 4) T AHA (time from first medical contact to 
reperfusion, as defined by the ACC/AHA guidelines). Note that in cases with direct presentation to the ER by walk-in, T AHA and T ER were identical.

Other important definitions used in this study were: 1) RRS (received reperfusion strategy), 2) NRS (no reperfusion strategy), 3) RRS-L (received reperfusion strategy - thrombolytics), and 4) RRS-P (received reperfusion strategy - PCI).

\section{Data Management and Analysis}

The collected data was subsequently entered into a database system (MS Excel, USA). Statistical analysis was completed with web-based software (15-16). The c2 analysis was used to compare categorical data, while the Wilcoxon test was used for the comparison of nonparametric, continuous dataset. A p-value of $<0.05$ was deemed to be statistically significant. Statistics were used to compare the following time intervals between 2003-4 and 2004-5: 1) T2, 2) T3, 3) T ER, and 4) T AHA. Following the aforementioned change in the subsequent year, we anticipated direct improvements in $\mathrm{T} 2$ and $\mathrm{T} 3$, with corresponding improvements in T ER and T AHA.

\section{RESULTS}

Preliminary results were presented elsewhere (17). In 2003-4, a total of 58 patients diagnosed as having STEMI were identified, and 41 (70.7\%) patients received reperfusion therapy. Of the patients who received reperfusion, $25(61.0 \%)$ patients received thrombolysis, while $16(39.0 \%)$ patients received primary PCI. In 2004-5, 52 patients presented with STEMI, with $40(76.9 \%)$ patients having received reperfusion therapy. Of these, 21 (52.5\%) patients and $19(47.5 \%)$ patients received thrombolysis and primary PCI, respectively. Overall, the unadjusted, in-hospital mortality rate for the entire group was $17 \%$ in $2003-4$ and $12 \%$ in $2004-5(\mathrm{p}=\mathrm{NS})$. Other significant demographic and clinical characteristics between the two groups are outlined in Table 1.
Table 1: Demographic and clinical characteristics

\begin{tabular}{lcc}
\hline \hline & $\begin{array}{c}\text { Total STEMI } \\
2003-2004\end{array}$ & $\begin{array}{c}\text { Total STEMI } \\
2004-2005\end{array}$ \\
\hline $\mathrm{N}$ & 58 & 52 \\
\hline Age (Mean+/- SD) & $64.5+/-14.0$ & $63.6+/-15.0$ \\
\hline Gender (\%Female) & 32.8 & 34.6 \\
\hline Mode (\%) & & 52.9 \\
\hline EMS & 39.7 & 47.1 \\
\hline ER & 60.3 & 96.2 \\
\hline Chest Pain (\%) & 90.0 & 38.5 \\
\hline Location (\%) & 41.4 & 74.5 \\
Anterior & 75.9 & 3.8 \\
\hline Killip Score (\%) & 14.0 & 8.0 \\
1 & 27.6 & 28.0 \\
\hline CRF (\%) & 37.9 & 8.0 \\
\hline Previous MI (\%) & 6.9 & 14.0 \\
\hline Previous Angina (\%) & 3.4 & 6.0 \\
\hline Previous CABG (\%) & 15.5 & 960 \\
\hline Previous PCTA (\%) & 5.2 & 2.76 \\
\hline Treated DM2 (\%) & 1173 & \\
\hline Previous CHF (\%) & 4.02 & \\
\hline Peak CK (median) & & \\
\hline Peak Trop (median) & & \\
\hline \hline
\end{tabular}

The specific time intervals for 2003-4 and 2004-5 are shown in Tables 2 and 3, respectively, with data recorded as the median time in minutes, including the 25th and 75th percentile.

In the initial year (2003-4), the time from ER to the first diagnostic EKG (T2) was 22 (13-33) minutes. For patients who received reperfusion, the treatment time (T3) was 20 (10-27) minutes in the thrombolysis group and 90 (73-214) minutes in the primary PCI group. In 2004-5, there was overall a non-significant, but positive trend toward improvement in T2, with 10 (7-39) minutes elapsing between ER presentation and the first diagnostic EKG $(\mathrm{p}=0.07)$. In comparison, T3 for thrombolysis $(19$ (11-34) minutes, $\mathrm{P}=0.27)$ and primary PCI (92 (71-118) minutes, $\mathrm{P}=0.39)$ was essentially unchanged.

Table 2: Specific time intervals for 2003-2004 $(n=58)$

\begin{tabular}{|c|c|c|c|c|c|}
\hline & Total STEMI & RRS STEMI & NRS STEMI & $\overline{\text { RRS-L }}$ & $\overline{\text { RRS-P }}$ \\
\hline T1 (Symptom onset - First medical contact) & $106(67-191)$ & $91(56-166)$ & $156(106-201)$ & $112(62-180)$ & $85(48-128)$ \\
\hline T2 (ER - Diagnostic EKG) & $22(13-33)$ & $17(12-28)$ & $29(22-53)$ & $17(13-25)$ & $18(12-28)$ \\
\hline T3 (Diagnostic EKG - Reperfusion) & & $42(14-80)$ & & $20(10-27)$ & $90(73-214)$ \\
\hline T ER (ER - Reperfusion) & & $72(31-119)$ & & $34(21-67)$ & $117(91-246)$ \\
\hline T AHA (First medical contact - Reperfusion) & & $81(49-124)$ & & $54(37-72)$ & $124(92-255)$ \\
\hline T Total (Symptom onset - Reperfusion) & & $166(123-330)$ & & $\overline{148(110-313)}$ & $195(144-483)$ \\
\hline
\end{tabular}

*All times stated as median (25th-75th percentile), in minutes

RRS - Received Reperfusion Strategy

NRS - No reperfusion strategy

RRS-L - Received Reperfusion Strategy - Lytics

RRS-P - Received Reperfusion Strategy - Primary PCI 
Table 3: Specific time intervals for 2004-2005 $(n=52)$

\begin{tabular}{|c|c|c|c|c|c|}
\hline & Total STEMI & "RRS STEMI & "NRS STEMI & $\overline{\text { RRS-L }}$ & $\overline{\text { RRS-P }}$ \\
\hline T1 (Symptom onset - First medical contact) & $96(66-147)$ & $101(70-155)$ & $96(30-100)$ & $94(60-150)$ & $108(73-215)$ \\
\hline T2 (ER - Diagnostic EKG) & $10(7-39)$ & $10(6-27)$ & $21(8-66)$ & $10(4-20)$ & $10(6-34)$ \\
\hline T3 (Diagnostic EKG - Reperfusion) & & $42(18-92)$ & & $19(11-34)$ & $92(71-118)$ \\
\hline T ER (ER - Reperfusion) & & $68(25-123)$ & & $28(18-59)$ & $104(91-137)$ \\
\hline T AHA (First medical contact - Reperfusion) & & $91(55-142)$ & & $58(43-78)$ & $139(101-162)$ \\
\hline T Total (Symptom onset - Reperfusion) & & $194(160-269)$ & & $187(120-260)$ & $204(176-272)$ \\
\hline
\end{tabular}

*All times stated as median (25th-75th percentile), in minutes

RRS - Received Reperfusion Strategy

NRS - No reperfusion strategy

RRS-L - Received Reperfusion Strategy - Lytics

RRS-P - Received Reperfusion Strategy - Primary PCI

As outlined in Tables 4 and 5 , the percentage of patients meeting the previous standard vs. the newer ACC/AHA guidelines between the 2 years was compared for thrombolysis and primary PCI. In general, fewer proportion of patients met the more stringent guidelines. There was no statistically significant difference in the proportion of patients receiving treatment in the recommended time window between 2003-4 and 2004-5.

\begin{tabular}{|c|c|c|c|}
\hline $\begin{array}{l}\text { Table 4: Percen } \\
\text { the previously } r \\
\text { ACC/AHA guid }\end{array}$ & $\begin{array}{l}\text { e of patient } \\
\text { mmended } \\
\text { nes between }\end{array}$ & $\begin{array}{l}\text { ceiving throm } \\
\text { lelines and the } \\
03-2004 \text { and } 2\end{array}$ & $\begin{array}{l}\text { is within } \\
\text { er } \\
005 \text {. }\end{array}$ \\
\hline & & Patients (\%) & P-value \\
\hline $\mathrm{T} \mathrm{ER}<30 \mathrm{~min}$ & $2003-2004$ & 40.0 & \\
\hline (Door-to-needle & $2004-2005$ & 52.4 & \\
\hline & & & $\overline{\mathrm{NS}}$ \\
\hline$\overline{\mathrm{T}} \mathrm{AHA}<30$ & $2003-2004$ & 12.0 & \\
\hline (First medical & $2004-2005$ & 14.3 & \\
\hline & & & NS \\
\hline
\end{tabular}

Table 5: Percentage of patients receiving thrombolysis within the previously recommended guidelines and the newer ACC/AHA guidelines between 2003-2004 and 2004-2005.

\begin{tabular}{l|c|c|c}
\hline & & Patients (\%) & P-value \\
\hline $\begin{array}{l}\text { T ER }<30 \text { min } \\
\text { (Door-to-needle } \\
\text { time) }\end{array}$ & $2003-2004$ & 25.0 & \\
\cline { 2 - 4 } & $2004-2005$ & 22.2 & \\
\cline { 2 - 4 } & & & NS \\
\hline $\begin{array}{l}\text { T AHA }<30 \\
\text { min } \\
\text { (First medical } \\
\text { contact to needle } \\
\text { time) }\end{array}$ & $2003-2004$ & 25.0 & \\
\cline { 2 - 4 } & & 11.1 & \\
\cline { 2 - 4 } & & & \\
\hline
\end{tabular}

\section{DISCUSSION AND CONCLUSIONS}

The purpose of this prospectively designed closedloop audit was to determine how one tertiary care center in Winnipeg compared to the new ACC/AHA prescribed treatment times for STEMI. This study is the first published audit of Canadian data specifically in comparison with the ACC/AHA guideline definition. The percentage of patients being treated in the optimal time period was unacceptably low in both years of the study, with even fewer patients meeting the more stringent guidelines.

Treatment times for hospital arrival to reperfusion (T ER) were comparable to previously published results (18-20). For example, in the FASTRAK II database, which is an ongoing, prospective registry of acute myocardial infarctions in Canada, the median time from hospital arrival to fibrinolytic treatment in 11,574 patients from 1998 to 2000 was 43 minutes, and only $27.4 \%$ of patients were treated within 30 minutes (18). Furthermore, in the AMI Quebec Study, where 1189 patients during the year 2003 were evaluated, the median door-to-needle time was 32 (20-49) minutes, with $48.8 \%$ of patients achieving the target of less than 30 minutes (19). The door-to-balloon time was 109 (79$150)$ minutes, and $35.5 \%$ of patients met the required goal of less than 90 minutes (19). In contrast, the more recent Calgary STEMI QIHI group showed an impressive median door-to-balloon time of 62 minutes, with $79 \%$ of patients meeting the prescribed time (21).

Following the implementation of a dedicated EKG machine in the ER and feedback of the previous year's results to the ER staff, it was expected that certain components of time delay would be shortened, leading to a concomitant improvement in reperfusion time in the subsequent year. Despite these changes, there was only a marginal improvement in the time to first diagnostic EKG, but this did not translate into meaningful reduction in time to reperfusion therapy.

The demonstration of the treatment times in this study indicates that systematic factors contributing to ongoing delay remain unidentified and unresolved. Improving patient-related factors to encourage earlier recognition of symptoms, and thus an overall reduction in the total ischemic time is essential, but interestingly, the REACT 
Study Group in the United States was unable to demonstrate that community intervention had a significant impact (22). Attempts to ameliorate inhospital delays such as the time to first EKG is the next logical time component to improve; however, we were unable to demonstrate this in our investigation. Furthermore, it would be provocative to look at the differences in reperfusion times in patients presenting via EMS or as a walk-in to the ER. We chose not to look at these differences in our study due to the small sample size, but certainly this would be important in a larger cohort of patients. Our institution is now in the process of attempting to coordinate EMS and ER services, as in many cases, the diagnosis of STEMI is known prior to ER presentation, but an ER EKG, for example, is invariably repeated (Personal communication; R.Grierson, WFPS/EMS Medical Director). Factors leading to delays in treatment after obtaining the EKG are uncertain, and we are looking further into local factors in an ongoing, prospective fashion. Finally, there is no local experience with pre-hospital thrombolysis, but published data in this area is increasingly provocative (23-26). Specifically, a meta-analysis comparing pre-hospital thrombolysis against in-hospital thrombolysis published in 2000 demonstrated a one hour reduction in time to thrombolysis and a $17 \%$ decrease in mortality (26). Furthermore, the pre-hospital diagnosis and transfer pathway for PCI developed in Calgary is another promising approach to finding a solution to this problem (21).

\section{Limitations}

There were some notable limitations in this study. Firstly, the sample size was small and included only 24 months of data. However, this was a homogenous sample representing patients from one tertiary care center within an urban region with five other acute care hospitals. Secondly, we were unable to provide a month-by-month evaluation of the hospital's performance; instead, we looked at the data annually. This is an important limitation, although it was imperative that we maintain the study in a true audit format, and by doing so, we were able to minimize the Hawthorne effect. The Hawthorne effect is a phenomenon whereby people may artificially change their behavior during a research study. If we had provided the ER physicians with monthly data as opposed to annual data, the Hawthorne effect would have likely been magnified, thus affecting our results. Thirdly, we looked at the time of administration of initial reperfusion strategy rather than the adequacy of reperfusion, defined as an open artery by EKG normalization and grade TIMI III flow. Finally, there is no local experience with pre-hospital thrombolysis and no defined established mechanism for the systematic use of primary PCI.

\section{Conclusion}

Treatment times are longer than the newly recommended ACC/AHA guidelines, with a minority of patients being treated in the optimal time period at our tertiary care center. More comprehensive strategies and improved coordination of medical services are required to shorten pre-contact and post-contact response times.

\section{REFERENCES}

1. Tu JV, Austin PC, Filate WA, Johansen HL, Brien SE, Pilote L, Alter DA. Outcomes of acute myocardial infarction in Canada. Can J Cardiol 2003; 19(8):893-901.

2. Guppo Italiano per lo studio della streptochinasi nell'infarcto miocardia (GISSI investigators). Effectiveness of intravenous thrombolytic treatment in acute myocardial infarction. Lancet 1986; 1:397-402.

3. ISIS-2 (Second International Study of Infarct Survival) Collaborative Group. Randomized trial of intravenous streptokinase, oral aspirin, both, or neither among 17,187 cases of suspected acute myocardial infarction: ISIS-2. Lancet 1988; 2:349-360.

4. The GUSTO investigators. An international randomized trial comparing four thrombolytic strategies for acute myocardial infarction. N Engl J Med 1993; 329:673-682.

5. Fibrinolytic Therapy Trialists' (FTT) Collaborative Group. Indications for fibrinolytic therapy in suspected acute myocardial infarction: collaborative overview of early mortality and major morbidity results from all randomized trials of more than 1000 patients. Lancet 1994; 343:311-322.

6. Grines $\mathrm{CL}$, Browne $\mathrm{KF}$, Marco $\mathrm{J}$ et al. for the Primary angioplasty in Myocardial Infarction (PAMI) Study Group. A comparison of immediate angioplasty with thrombolytic therapy for acute myocardial infarction. N Engl J Med 1993; 328:673679 .

7. Anderson HR, Nielsen TT, Rasmussen K, Thuesen L, Kelbaek $\mathrm{H}$, Thayssen $\mathrm{P}$, et al. (DANAMI-2 Investigators). A Comparison of Coronary Angioplasty with Fibrinolytic Therapy in Acute Myocardial Infarction. N Engl J Med 2003; 349(8):733-742.

8. Keeley EC, Boura JA, Grines CL. Primary angioplasty versus intravenous thrombolytic therapy for acute myocardial infarction: a quantitative review of 23 randomized trials. Lancet 2003; 361:13-20.

9. Nallamothu BK, Bates ER. Percutaneous coronary intervention versus Fibrinolytic Therapy in Acute Myocardial Infarction: Is Timing (Almost) Everything?. Am J Cardiol 2003; 92:824-826.

10. Giugliano RP, Braunwald E. Selecting the Best Reperfusion Strategy in ST-Elevation Myocardial Infarction: It's All a Matter of Time. Circulation 2003; 108:2828-30.

11. Gersh BJ, Stone GW, White HD, Holmes DR. Pharmacological Facilitation of Primary Percutaneous Coronary Intervention for Acute Myocardial Infarction: Is the Slope of the Curve the Shape of the Future? JAMA 2005; 293:979-986.

12. ACC/AHA Guidelines for the Management of Patients with STElevation Myocardial Infarction: Executive Summary. J Am Coll Cardiol 2004; 44:671-719.

13. Armstrong PW, Bogarty P, Buller CE, Dorian P, O'Neill BJ. The 2004 ACC/AHA Guidelines: a perspective and adaptation for Canada by the Canadian Cardiovascular Society Working Group. Can J Cardiol 2004; 20(11):1075-9.

14. 1999 Update: ACC/AHA Guidelines for the Management of 
Patients With Acute Myocardial Infarction: Executive Summary and Recommendations. Circ 1999; 100:1016-30.

15. Interactive Resources and On-line Material. Department of Quantitative Psychology, University of Kansas. http://www.quantpsy.org/ (August 10, 2006).

16. Vassar Stats: Website for Statistical Computation. Richard Lowry, Vassar College. http://faculty.vassar.edu/lowry/wilcoxan.html/ (1998-2006).

17. Bhagirath KM, Kass M, Chochinov AH, Avery L, Hall L, Tam JW. Prompt treatment of STEMI: A Race Against the Clock. Can J Cardiol 2005; 21 Supplement C: Abstract 491, 166C.

18. Davies C, Christenson J, Campbell A, Cox JL, Huynh T, Matheson S et al. FASTRAK II Network. Fibrinolytic therapy in acute myocardial infarction: Time to treatment in Canada. Can J Cardiol 2004; 20(8):801-805.

19. Huynh T, O'Loughlin J, Joseph L, Schampaert E, Rinfret S, Afilalo $\mathrm{M}$ et al. Delays to reperfusion therapy in acute STsegment elevation myocardial infarction: results from the AMIQuebec Study. CMAJ 2006; 175(12):1527-32.

20. Kereiakes DJ, Weaver WD, Anderson JL, Feldman T, Gibler B, Aufderheide $\mathrm{T}$ et al. Time delays in the diagnosis and treatment of acute myocardial infarction: A tale of eight cities: Report from the Pre-hospital Study Group and the Cincinnati Heart Project. Am Heart J 1990; 120:773-780.

21. De Villiers JS, Anderson T, McMeekin JD, Leung RCM, Traboulsi M. Expedited transfer for primary percutaneous coronary intervention: a program evaluation. CMAJ 2007; 176(13):1833-8.

22. Hedges JR, Feldman HA, Bittner V, Goldberg RJ, Zapka J,
Osganian SK, et al. the REACT Study Group. Impact of Community Intervention to Reduce Patient Delay Time on Use of Reperfusion Therapy for Acute Myocardial Infarction: Rapid Early Action for Coronary Treatment (REACT) Trial. Acad Emerg Med 2000; 7:862-872.

23. Bonnefoy E, Lapostolle F, Leizorovicz A, Steg G, McFadden EP, Dubien PY et al. CAPTIM Study Group. Primary angioplasty versus prehospital fibrinolysis in acute myocardial infarction: a randomized study. Lancet 2002; 360:825-829.

24. Armstrong PW, WEST Steering Committee. A comparison of pharmacologic therapy with/without timely coronary intervention vs. primary percutaneous intervention early after ST-elevation myocardial infarction: the WEST (Which Early ST-elevation myocardial infarction Therapy) study. European Heart Journal 2006; 27:1530-1538.

25. Bjorklund E, Stenestrand U, Lindback J, Svensson L, Wallentin L, Lindahl B, RIKS-HIA Investigators. Pre-hospital thrombolysis delivered by paramedics is associated with reduced time delay and mortality in ambulance-transported reallife patients with ST-elevation myocardial infarction. European Heart Journal 2006; 27:1146-1152.

26. Morrison LJ, Verbeek PR, McDonald AC, Sawadsky BV, Cook DJ. Mortality and Prehospital Thrombolysis for Acute Myocardial Infarction: A Meta-analysis. JAMA 2000; 283(20):2686-2692.

Kapil M Bhagirath, MD, Kendeep S Kaila, BSc MD, a first-year resident in Internal Medicine, Malek Kass, MD FRCPC, and James W Tam, MD FRCPC, are part of the Department of Medicine, Section of Cardiology at the University of Manitoba. Lorraine Avery, RN BN MN CNCC(C), Lillian Hall, RN BHScN CNCC(C), are part of the Winnipeg Regional Health Authority (WRHA) Cardiac Sciences Program and Cardiac Rehabilitation in Winnipeg, Manitoba. Alex H Chochinov, MD is a member of the Department of Emergency Medicine, St. Boniface General Hospital, University of Manitoba. 